\title{
ТЕОРЕТИКО-МЕТОДОЛОГИЧЕСКИЕ ИССЛЕДОВАНИЯ РЕГИОНАЛЬНЫХ ИНТЕГРАЦИОННЫХ МОДЕЛЕЙ ЭКОНОМИЧЕСКОГО РАЗВИТИЯ СОВРЕМЕННЫХ ГОСУДАРСТВ: СИСТЕМНЫЙ ПОДХОД
}

\author{
(C) 2019 Бу Тун \\ стажер кафедры Экономической теории и менеджмента \\ Московский педагогический государственный университет, Россия, Москва \\ E-mail: Chairt.etm@bk.ru \\ ( 2019 Платонова Елена Дмитриевна \\ доктор экономических наук, профессор, \\ заведующий кафедрой Экономической теории и менеджмента \\ Московский педагогический государственный университет, Россия, Москва \\ E-mail: etm@mpgu.edu
}

\begin{abstract}
Актуальность разработки современной теоретической концепции создания и развития региональных интеграционных экономических объединений стран с развивающимися рынками обусловила поиск теоретико-методологических оснований данной концепции на основе обращения к системному подходу как методологическому инструменту анализа исторического опыта Совета экономической взаимопомощи (СЭВ) и методологической позиции экономистов институционального направления.
\end{abstract}

Ключевые слова: региональные интеграционные объединения, страны с развивающимися рынками, международная экономическая интеграция, социалистическая экономическая интеграция, системный подход, институционализм.

Начиная с 90-х годов прошлого века, развитие региональных интеграционных экономических объединений стран с развивающимися рынками следует характеризовать как наиболее яркое проявление закономерностей современного этапа глобализации. В данном контексте мировая экономика является не столько совокупностью национально-государственных систем, сколько определяется функционированием региональных интеграционных экономических объединений стран с различным уровнем экономического развития и глубиной проникновения рыночных отношений в системы жизнеобеспечения интегрируемых государств.

В настоящее время в экономических исследованиях генезис региональных интеграционных экономических объединений стран рассматривается большинством теоретиков и практиков через призму рассмотрения таких понятий как международное разделение труда, международные экономические отношения, глобализация, международная региональная интеграция [9]. По существу, пока не прослеживается целостная концепция создания и развития региональных экономических группировок стран с развивающимися рынками. Вместе с тем, разработка данной концепции выступает актуальной научно-теоретической и научно-практической задачей, на основе решения которой должна выстраиваться экономическая политика России и КНР и придан импульс к интенсификации развития уже созданных интеграционных образований (ЕАЭС, ШОС, БРИКС). Однако, по нашему мнению, экономистами прошлого и настоящего созданы необходимые теоретикометодологические подходы к формированию данной концепции, а в практике имеется опыт функционирования межгосударственных региональных интеграционных моделей экономического развития (СЭВ, ЕС, ЕАЭС и др.).

Наиболее плодотворным в исследовании опыта интеграционного взаимодействия государств выступает использование методологического потенциала системного подхода [10]. Именно данный подход позволяет рассматривать выработанные экономистами дефиниции (кооперация, сотрудничество, международная торговля и др.) в качестве элементов теоретической системы, характеризующих интеграционные процессы на региональном уровне между заинтересованными государствами, выступаю- 
щими субъектами региональной экономической интеграции. В этом контексте следует указать на высказанную ранее нами позицию о том, что гибкость «концептуального каркаса системного подхода позволяет значительно углубить содержательную сторону знания о предмете исследования, сосредоточивая внимание экономистов на описании сторон, свойств и взаимосвязей элементов внутри предмета исследования (подсистемы), анализе его роли и места в системе более высокого порядка, взаимозависимостей от социальной и природной окружающей среды» $[11$, C.6].

Анализ трудов советских и российских экономистов, а также актуальных работ китайских исследователей, позволяет сделать вывод о достаточно широком применении элементов системного подхода к изучению феноменов экономической интеграции, которые возникали в различные исторические периоды, в том числе, в послевоенный период и в наши дни.

Активизация процесса теоретического осмысления советскими экономистами интеграционных процессов между государствами, которые возникли в Евразии по результатам окончания Второй мировой войны, связано в первую очередь с образованием Совета экономической взаимопомощи (СЭВ, 1949) и Европейского объединения угля и стали (ЕОУС, 1951), который заложил основы современного, наиболее развитого регионального экономического объединения - Европейского Союза (Объединенной Европы).

Создание межправительственной экономической организации СЭВ инициировалось СССР и странами учредителями - Болгарии, Венгрии, Польши, Румынии, Чехословакии, которые выбрали социалистическую ориентацию своего социально-экономического развития. Состав членов СЭВ свидетельствует о том, что данная организация создавалась как региональная организация, охватывающая экономики европейских стран в условиях противостояния политики западных стран и реализации ими «плана Маршалла». Позднее к СЭВ присоединились другие страны социалистического лагеря - Вьетнам, гДР, Куба, Монголия. В определенные периоды в работе СЭВ участвовала Албания, а в отдельных проектах - Югославия. Статус страннаблюдателей имели КНР (до 1966), Ангола, Афганистан, Лаос, Эфиопия и ряд других стран. Участие стран, территориально расположенных в разных частях света и континентах, позволяет охарактеризовать данное объединение государств, проводящих целенаправленную интеграционную экономическую политику, не только как евразийское, но и трансконтинентальное.

Изначально функционирование СЭВ, как интеграционной модели экономического развития, рассматривалась советскими исследователями и учеными стран-участниц СЭВ с позиции формирования социалистической системы мирового хозяйства (ССMX) на основе поэтапного эволюционного развития (О. Богомолов, М. Сенин, Н. Шмелев и др.). На анализ развития ССМХ значительное влияние оказал тезис В.И. Ленина о тенденции «к созданию единого, по общему плану регулируемого пролетариатом всех наций, всемирного хозяйства как целого, каковая тенденция вполне явственно обнаружена уже при капитализме и безусловно подлежит дальнейшему развитию и полному завершению при социализме" [6, С.164]. Вера в истинность данного тезиса среди ученых, разделявших социалдемократические убеждения, объясняется тем, что он отражал не только новую послевоенную ситуацию, но и показывал перспективу экономического развития стран, объединившихся в СЭВ. Вместе с тем, данный тезис опирался на хрестоматийное положение социал-демократического учения К. Маркса и Ф. Энгельса о том, что на «смену старой местной и национальной замкнутости и существованию за счет продуктов собственного производства приходит всесторонняя связь и всесторонняя зависимость наций друг от друга» [7, С.428].

Интеграционные процессы в рамках ССMX требуют определенной зрелости социалистического способа производства и его укоренения в каждой из стран-членов СЭВ. Однако в начале 50-х годов прошлого века в европейских странах народной демократии, которые вошли в СЭВ, только происходили коренные социальноэкономические преобразования под руководством политических партий, провозгласивших курс на построение социализма. В этой связи следует отметить, что в принятом в 1959 году Уставе СЭВ, закономерно не применялся термин «социалистическая экономическая интеграция», а акцентировалось внимание на экономическом и научно-техническом сотрудничестве странчленов Совета, которое «осуществляется в соответствии с принципами полного равноправия, уважения суверенитета и национальных инте- 
ресов, взаимной выгоды и товарищеской взаимопомощи», а также направлено на повышение «уровня индустриализации стран с менее развитой промышленностью, непрерывному росту производительности труда и неуклонному подъему благосостояния народов стран - членов Совета» [13].

В конце 60-х годов прошлого века происходящие на практике интеграционные процессы в CСMX потребовали от экономистов теоретического обоснования нового концепта - «социалистической экономической интеграции» (СЭИ), который являлся, по мнению исследователей, альтернативой капиталистической интеграции и рассматривалась как ее противоположность. В этой связи были подвергнуты острой критики теории международной экономической интеграции, выработанные западными учеными на основе обобщения интеграционной практики капиталистических стран (федерализм, функционализм, неофункционализм, интерговерментализм и др.). Необходимо отметить, что на протяжении всего периода функционирования СЭВ советскими исследователями, а также многими экономистами из стран-членов СЭВ, при описании интеграционных процессов достаточно часто использовался методологический прием жесткого противопоставления «социалистическое - капиталистическое» в содержании интеграционных процессов под влиянием идеологических установок и преувеличения роли таких внеэкономических дефиниций как «пролетарский интернационализм», «товарищеская взаимопомощь», «братская солидарность», «нерушимое единство», которые отражали ведущую роль политических и институциональных факторов в развитии ССМХ. Как показали дальнейшие исторические события 90-х годов 20 века именно геополитические факторы оказали решающее влияние на роспуск СЭВ и ликвидацию ССМХ.

Несмотря на то, что в рассматриваемый период теоретическая проработка концепта СЭИ, как основы развития интеграционной модели СЭВ, была далека от своего завершения, в большинстве работ прослеживается применение системного подхода к раскрытию содержания СЭИ и определению ее места в системе производственных отношений социалистических государств.

В оригинальных суждениях экономистов стран-членов СЭВ можно зафиксировать преемственность с методологическими идеями, характерными для сущностной общенаучной концепции. Такой вывод вытекает из стремления исследователей показать сущность СЭИ и охарактеризовать СЭИ как систему межгосударственных воспроизводственных отношений, направленных на тесное взаимодействие и сближение национальных хозяйств с последующим объединением на основе планомерного развития и социалистической собственности и формированием высокоэффективного народнохозяйственного комплекса СЭВ.

В экономической литературе стран социалистического лагеря в период с 70-х по 90-е годы 20 века представлены различные системные построения, отражающие содержание и формы СЭИ. С точки зрения рассмотрения интеграционных отношений, характеризующих содержание СЭИ, и анализа работ советских экономистов можно выделить такие сложные элементы как отношения, возникающие в совместной плановой деятельности; отношения производственного кооперирования и специализации; отношения научно-технического сотрудничества; отношения товарообмена и экспортноимпортные отношения; кредитно-валютные и расчетные отношения; логистические отношения. Данная подсистема отношений в интеграционной модели экономического развития СЭИ рассматривается в качестве подсистемы отношений более высокого порядка - системы международных производственных отношений, которая возникает между странами, образующими CCMX.

С развитием концепции Л. Абалкина о содержании и роли организационно-экономических отношений и введением в широкий научный оборот концепта «хозяйственный механизм» многие авторы используют данное понятие как системный конструкт, выделяя отношения планирования, управления, стимулирования [1]. Ведущая роль в хозяйственном механизме СЭВ отводилась координации народнохозяйственных планов, что отражает действие и использования экономического закона планомерного развития на уровне межгосударственных отношений и порождает новую - международную планомерность [2]. Данная теоретическая установка была реализована не только авторами программного документа СЭВ - «Комплексной программы дальнейшего углубления и совершенствования сотрудничества и развития социалистической экономической интеграции стран - членов 
СЭВ» (1971), но главным образом в процессе разработки долгосрочных целевых программ СЭИ в конце 70-х и начале 80x годов прошлого века.

K развитию положений системного подхода можно отнести применение методологии уровневого исследования межгосударственных региональных интеграционных моделей экономического развития на примере СЭВ. Выделение уровней - первичного звена (предприятия), отрасли, народного хозяйства в целом (государства) и ССМХ - позволяет углубить представление о субъектах, реализующих системные отношения СЭИ (системную совокупность экономических агентов).

В последние годы работы СЭВ особое внимание со стороны партийно-государственных органов стран-членов СЭВ было уделено первичному звену социалистической системы хозяйствования, поскольку стало очевидным, что именно от наличия (отсутствия) экономического интереса к сотрудничеству и производственной интеграции (горизонтальной, или вертикальной) предприятий, функционирующих в экономическом пространстве СЭВ, зависит жизнеспособность данной интеграционной модели и ее эффективность. Вместе с тем, уровневый анализ показал, что в условиях монополии государств на внешнюю торговлю и установление административным путем цен на продукцию теряется быстрота реакции предприятий на внешнее экономическое окружение, утрачиваются конкурентные преимущества СЭИ и предприятия «тянутся» к свободному капиталистическому рынку.

Несмотря на успехи функционирования СЭВ как интеграционной модели социалистических государств, к середине 80-х годов прошлого века накопились экономические проблемы, связанные, в первую очередь, с обоснованием закономерностей развития мирового социалистического рынка и трудностями с установлением плановых цен на готовую продукцию, топливо, сырье, материалы. В условиях быстро развивающегося научно-технического прогресса и давления свободного капиталистического рынка предприятия, включенные в интеграционные процессы в рамках СЭВ, стали все более экономически заинтересованными в установлении прямых экспортно-импортных отношений с партнерами по производственной кооперации на взаимовыгодных условиях с расчетами в конвертируемой валюте.
Определенным шагом в преодолении жесткого администрирования экспортно-импортных операций должны были стать совместные предприятия стран-членов СЭВ для объединения научно-технического и производственного потенциала стран социалистического содружества [8]. Созданные совместные предприятия (например, «Интерметалл», «Интерхим», «Интрансмаш», «Агромаш» и др.) искали пути повышения эффективности и конкурентоспособности в условиях значительного влияния геополитических факторов (соревнование двух систем, гонка вооружений и др.).

Появление совместных предприятий и холдингов позволило расширить «уровневый» ряд экономических агентов СЭИ, включив мезоуровень - вертикально или горизонтально интегрированные предприятия, производственноторговые площадки которых охватывали экономическое пространство многих стран СЭВ. Вместе с тем, их работа показала, что институты государственной монополии внешней торговли существенно увеличивают трансакционные издержки бизнеса, что делало продукцию международных социалистических объединений менее конкурентоспособной по сравнению с функционированием капиталистических ТНК, несмотря на то, что в основном она сбывалась на международном социалистическом рынке.

На ведущей роли крупного бизнеса в региональных интеграционных процессах, протекавших в капиталистических и развивающихся странах, настаивают представители институционального направления западной экономической мысли. Элементы системного подхода прослеживаются в исследованиях роли и места транснациональных корпораций (ТНК) представителями корпорационализма (С. Рольф, У. Ростоу и др.).

При рассмотрении совокупности экономических агентов, которые оперируют в интегрируемом экономическом пространстве, ТНК отводится системообразующая роль. Как верно отмечают российские исследователи, «ТНК являются плацдармом для активизации инвестиционных процессов, структурной перестройки, модернизации производства, оказывая непосредственное воздействие на диверсификацию номенклатуры товарной продукции, пополнение потребительского рынка и наращивание объемов экспорта» [3, С. 370]. Это позволяет корпорациям осуществлять экономическую власть, 
которую они направляют на интенсификацию процесса интегрирования экономик стран, входящих в региональные группировки. При этом «международное разделение труда и сферы сотрудничества фактически превращаются во внутреннее разделение труда и сотрудничество ТНК. Когда транснациональные корпорации пользуются преимуществами и ведут крупномасштабную и глобальную ... деятельность, тогда их объективная цель состоит в том, чтобы способствовать развитию экономической интеграции и глобализации» [14]. Особенностью данного подхода выступает то, что в системе экономических механизмов, влияющих на межгосударственные процессы интеграционного развития, на первый план выводятся не рынок и государство, а именно трансграничные возможности ТНК. Более того, именно они противопоставляются эффективности воздействия на интеграционные взаимодействия экономических субъектов рыночным механизмам и государственному регулированию.

Рядом западных авторов неоинституционального направления (А. Алчайн, Р. Коуз, О. Уильямсон и др.) ведущая экономическая роль ТНК в интеграционных моделях западных стран обосновывается на основе положений теории трансакционных издержек. Так, следует поддержать позицию автора, согласно которой неоинституционалисты, в частности О. Уильямсон, объясняют «содержательную сторону интеграции наличием экономических взаимозависимостей, связанных с сокращением трансакционных затрат при замене рынка внутренней организацией» $[4$, С.251].

С позиции применения системного подхода к исследованию интеграционных моделей экономического развития государств в послевоенный период, в частности, ЕС представляется интересной «структурная» концепция интеграции, предложенная Г. Мюрдалем, Ф. Перу и другими представителями структурализма. Они рассматривали интеграционные процессы в единстве экономических, социальных и институциональных явлений (факторов), характерных для экономик интегрирующихся стран. При этом один из ведущих представителей структурализма Г. Мюрдаль указывал на необходимость структурных изменений в воспроизводственном процессе формирования интеграционной модели государств, результатом которых будет новое системное образование - целостное интегриро- ванное пространство.

В данной социально-экономической системе взаимодействуют различные факторы, а изменение в одном факторе вызывают изменения в других факторах и всей системы в целом. Вместе с тем, Г. Мюрдаль при изучении интеграционной модели экономического развития государств значительную роль отводил социальным факторам и проблеме «смягчение социальной жёсткости, которая мешает индивидуумам свободно выбирать условия их труда и жизни» [5, C.38]. По мнению исследователя, в региональных интеграционных объединениях промышленно развитых стран достигнута высокая степень экономической интеграции. Однако в системе международных экономических отношений наблюдается усиление роста экономического неравенства между развитыми и слаборазвитыми странами, что свидетельствует о дезинтеграции в системе мирового хозяйства и дисфункции институтов интеграции.

Анализ концептуальных позиций представителей институционализма во всех его версиях показывает, что на формирование теоретических конструктов, отражающих интеграционные процессы и развитие региональных интеграционных моделей достаточно большое влияние оказывала системная метаметодологическая концепция. На ее основе выстраивались оригинальные построения, которые позволяли установить функциональные взаимосвязи и взаимозависимости внутренних и внешних факторов, обусловливающих интеграционный вектор развития мировой экономики. В этой связи необходимо отметить, что в институциональных построениях экономического пространства региональных межгосударственных объединений, которые создавались западными исследователями, прослеживается определенная преемственность с методологическими положениями, свойственными функциональной общенаучной концепции [12]. Это относится к исследовательским инструментам, которые использовались при установлении функциональных зависимостей между факторами, воздействующих на экономических агентов, участвующих в интеграционных процессах, а также расчетных операциях для подтверждения научных гипотез.

На основании сделанного анализа можно сделать следующие выводы:

- социал-демократические концепции международной экономической интеграции, лежа- 
щей в основе интеграционных моделей, включая теоретические построения в советский период, создавались преимущественно под влиянием системного общенаучного подхода с выделением сущностного (основного) отношения в системе международных экономических взаимосвязей;

- институциональный подход к процессам международной экономической интеграции и формированию региональных интеграционных моделей экономического развития государств характеризуется разнообразием институциональных построений, которые сформировались преимущественно под воздействием системно- го общенаучного подхода с элементами, свойственными функциональной методологии экономических исследований.

Полученные из проведенного исследования позволяют углубить представление о теоретикометодологических подходах, которые применяли экономисты при исследовании актуальной в настоящее проблемы создания и развития межгосударственных интеграционных экономических объединений, а также продолжить поиск адекватных теоретико-методологических оснований концепции создания и развития интеграционных экономических объединений стран с развивающимися рынками.

\section{Библиографический список}

1. Абалкин Л.И. Сущность, структура и актуальные проблемы совершенствования хозяйственного механизма // Экономические науки, 1978, № 8, с.33-44.

2. Белов А.В. Международная планомерность и методы её реализации (на опыте сотрудничества странчленов СЭВ). Автореф....канд.экон. наук.Леннград, 1984.- 24 с.

3. Гущян А.Ф. Основные концепции международной экономической интеграции // Экономические науки, 2009, № 6(55). С.370-372.

4. Долгих Е.Л. Институциональный подход к исследованию феномена стратегической интеграции // Известия Тульского государственного университета. Экономические и юридические науки.2015, № 1-4.С.249-258

5. Игумнов О.А. Международная экономическая интеграция: теоретические аспекты/ Пространственная экономика: проблемы региональных экономических объединений: Материалы XIII Международной научной конференции. М.: МПГУ, 2015. С.27-50

6. Ленин В.И. Тезисы ко П Конгрессу Коммунистического Интернационала / Ленин В.И. Полн.собр.соч. Изд.5-е.Т.41. М.: Политиздат, 1981-696 с.

7. Маркс К., Энгельс Ф. Манифест Коммунистической партии/ Маркс К., Энгельс Ф. Соч.2-е изд., т.4. - 616 с.

8. О порядке создания на территории СССН и деятельности совместных предприятий, международных объединений и организаций СССР и других стран - членов СЭВ. Постановление Совета министров СССР от 13 января 1987 г. N48.URL: https://docs.cntd.ru/document/9026949

9. Платонова Е.Д., Бу Тун. Развитие интеграционных объединений стран с развивающимися рынками как закономерность мировой экономики: исследовательские подходы // Пространственная экономика: проблемы региональных экономических объединений: Материалы XV Международной научной конференции. 23 июня 2017 г. Москва, Россия. М: Перо, 2018.С.70-73

10. Платонова Е.Д. Экономическое исследование: вопросы методологии. Монография.М.: АПКиППРО, 2016.$135 \mathrm{c}$.

11. Платонова Е.Д., Платонов А.Ю., Ягодкина И.А., Емельянов А.А. О методологическом ресурсе системного исследования экономики // Интернет-журнал «Науковедение». 2012. № 4 (13).URL: http://naukovedenie.ru/ PDF/129evn412.pdf

12. Платонова Е.Д., Ягодкина И.А., Улитина Е.В., Богомолова Ю.И. Влияние смены метаметодологических концепций на эволюцию экономической теории // Интернет-журнал Науковедение. 2013. № 1 (14) - URL: http://naukovedenie.ru/PDF/16evn113.pdfсвободный. - Загл. с экрана.-Яз. рус., англ.

13. Устав Совета экономической взаимопомощи (София, 14 декабря 1959 года) - URL: www.zaki.ru/pagesnew. php?id=1401 \&page $=1$

14. 华民, 经济全球化与中国的对外开放, 《学术月刊》, 2007年, 39, 7月号(200433), 第63页 [Хуа Мин. Экономическая глобализация и открытость Китая внешнему миру // Academic Monthly, Jul., 2007, Vol. 39, № . 7 (200433), c. 63]. 